\title{
Variations of aerosol optical depth and Angstrom parameters at a suburban location in Iran during 2009-2010
}

\author{
M Khoshsima $^{1, *}$, A A Bidokhti ${ }^{2}$ and F Ahmadi-Givi ${ }^{2}$ \\ ${ }^{1}$ Department of Meteorology, Science and Research Branch, Islamic Azad University, Tehran, Iran. \\ ${ }^{2}$ Institute of Geophysics, University of Tehran, Tehran, P. O. Box 14155-6466, Iran. \\ *Corresponding author.e-mail: khoshsima@alumni.ut.ac.ir
}

Solar irradiance is attenuated spectrally when passing through the earth's atmosphere and it is strongly dependent on sky conditions, cleanliness of the atmosphere, composition of aerosols and gaseous constituents. In this paper, aerosol optical properties including aerosol optical depth (AOD), Angstrom exponent $(\alpha)$ and Angstrom turbidity coefficient $(\beta)$ have been investigated during December 2009 to October 2010, in a suburban area of Zanjan $\left(36^{\circ} \mathrm{N}, 43^{\circ} \mathrm{E}, 1700 \mathrm{~m}\right)$, in the north-west of Iran, using meteorological and sun photometric data. Results show that turbidity varies on all time scales, from the seasonal to hourly, because of changes in the atmospheric meteorological parameters. The values of $\alpha$ range from near zero to 1.67. The diurnal variation of AOD in Zanjan is about $15 \%$. The diurnal variability of AOD, showed a similar variation pattern in spring (including March, April, May) and winter (December, January, February) and had a different variation pattern in summer (June, July, August) and autumn (September and October). During February, spring and early summer winds transport continental aerosols mostly from the Iraq (dust events) and cause the increase of beta and turbidity of atmosphere of Zanjan.

\section{Introduction}

Suspended aerosol particles in the atmosphere, apart from health effects and indirect effects on clouds, play a significant role in global change issues, since they influence the earth's radiation balance and climate by scattering or absorbing both incoming and outgoing radiation. Tropospheric aerosols arise from natural sources, such as airborne dust, seaspray and volcanoes and from anthropogenic sources, such as sulfate, ammonium, nitrate and also from gas-to particle conversion processes (Seinfeld and Pandis 1998; Satheesh and Ramanathan 2000; Lelieveld 2001; Ramanathan et al. 2001).
On a global scale, the natural sources of aerosols are more important than the anthropogenic aerosols, but regionally anthropogenic aerosols are significant (Coakley et al. 1983; Kaufman and Fraser 1983; Coakley and Cess 1985; Kiehl and Breigleb 1993; Andreae 1995; Ramanathan et al. 2001; Satheesh and Moorthy 2005).

Solar irradiance is attenuated spectrally when passing through the Earth's atmosphere. Attenuation of solar irradiance is strongly dependent on sky conditions, cleanliness of the atmosphere, and composition of aerosols and gaseous constituents. In a clean and dry atmospheric condition, solar irradiance is attenuated by atmospheric constituents

Keywords. Turbidity; aerosol optical depth; Angstrom exponent; suburban area; sun photometer; Zanjan. 


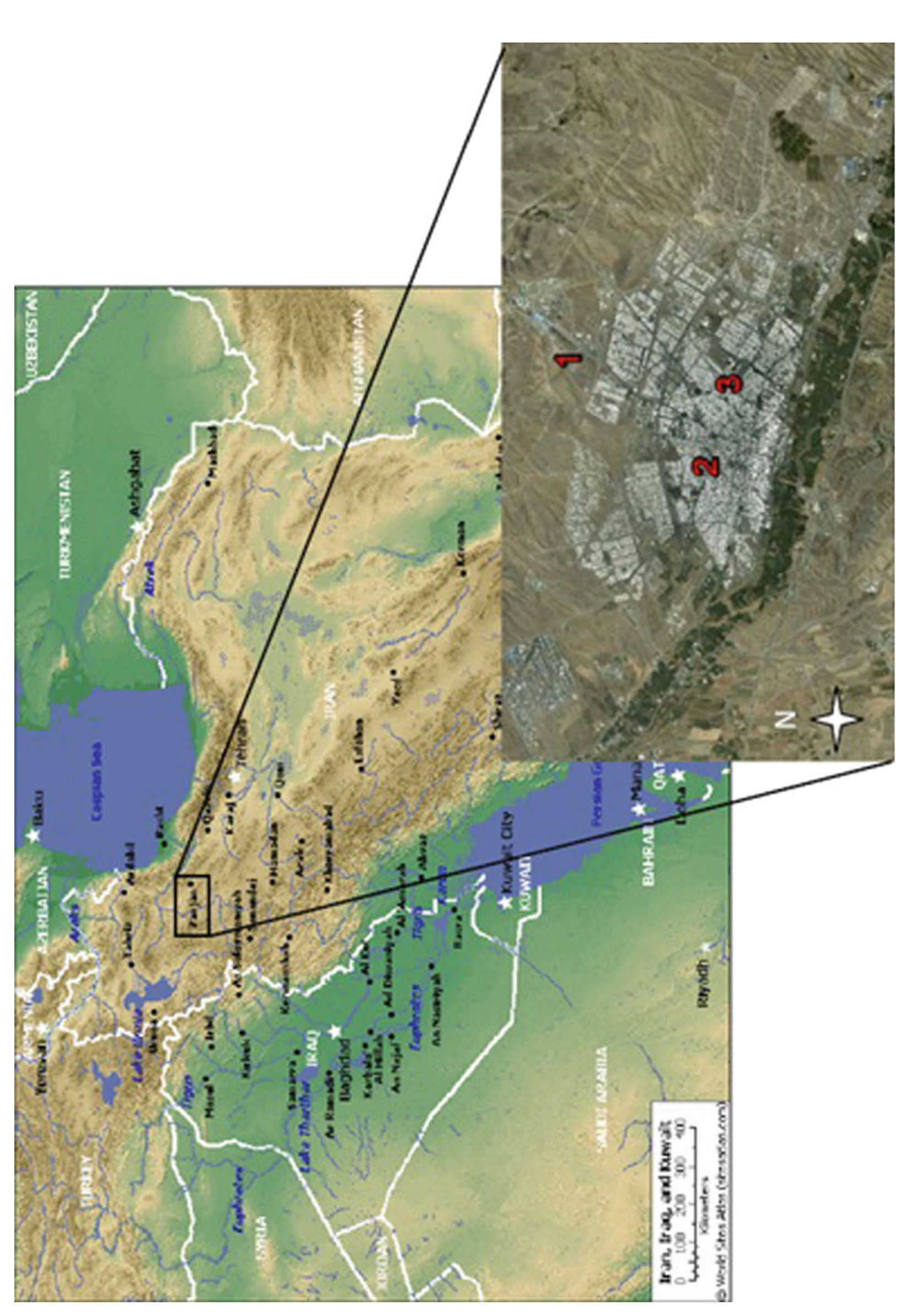

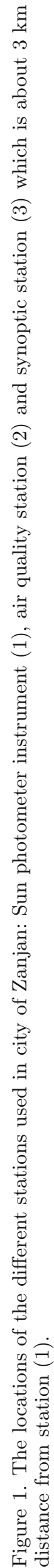


of air molecules, gases, whose contents are nearly invariable.

In the real atmosphere, the light attenuation processes are augmented by aerosol particles scattering and absorption by water vapour. The attenuation caused by these two processes leads to atmospheric turbidity (Braslau and Dave 1973; Hainel et al. 1990; Jacovides et al. 1994).

Turbidity is a dimensionless measure of the opacity of a vertical column of the atmosphere. Parameters such as the Angstrom indices $(\alpha$ and $\beta)$ and aerosol optical depth (AOD) are typically used for atmospheric aerosol optical properties. Angstrom turbidity coefficient $(\beta)$ is used as a measure of turbidity. Knowing the atmospheric turbidity coefficients is very important in prediction of the availability of solar energy under cloudless skies. Observations of aerosol parameters and turbidity over the land and ocean can be measured using a variety of instruments on different platforms such as active (e.g., LIDAR) and passive (sun photometer and satellite) remote sensing techniques (Moorthy et al. 2005; Kokhanovsky 2008).

The Angstrom exponent dependence on aerosol optical depth has been investigated in Asia and Africa by several authors (e.g. Moorthy and Satheesh 2000; Cachorro et al. 2001; Cheng et al. 2006; Kaskaoutis et al. 2007; Ogunjobi et al. 2008) to determine different aerosol types for specific locations. The relationship between AOD and Angstrom exponent is also used in order to explain the dependence of aerosol loading on particle size. Several studies have been carried out on the aerosol properties over Asia using such relationships (e.g., Indian, Bay of Bengal and Arabian Sea by Nakajima and Higurashi 1998; Hussain et al. 2000; Moorthy et al. 2003, 2005; Zakey et al. 2004; Satheesh and Moorthy 2005, 2006; Ping Guo et al. 2009; Chih-Chung and Hui-HsuanYeh 2010; Lodhi et al. 2013).

Also many studies concerning atmospheric turbidity and aerosol optical properties in different parts of the world (America and Europe) have been performed (Polavarapu 1978; Canada et al. 1993; Gueymard and Garrison 1998; Gueymard and Vignola 1998; Cucumo et al. 1999, 2000; Rapti 2000; Hand et al. 2004). However, a few works have been carried out in the Middle-East region of Asia. The limited number of studies on the atmospheric optical properties in this region makes it worth investigating even for a local region (WMO 1994). Aerosol optical properties and turbidity vary with local meteorological conditions and sources of natural and anthropogenic aerosols. Therefore, study of aerosol optical properties and turbidity should be determined regionally.

In this study, atmospheric optical properties were investigated for the city of Zanjan $\left(36^{\circ} \mathrm{N}\right.$, $43^{\circ} \mathrm{E}$ ), located around $1700 \mathrm{~m}$ above sea level on a wide plain in the north-west of Iran (figure 1). The city lies in a valley between the two mountains. The annual mean of temperature in the last 33 years is $10.7^{\circ} \mathrm{C}$, precipitation is $295 \mathrm{~mm}$ and relative humidity is around $53 \%$.

The structure of this paper is as follows. In section 2, we present the instrumentation and data collection, such as sun photometric measurements used to calculate the AOD and Angstrom indices $(\alpha, \beta)$. The field measurement analysis and more discussion on aerosol optical properties parameters are given in section 3 . Finally the conclusion of this work will be presented in section 4 .

\section{Instrumentation, data collection and analysis}

\subsection{Aerosol optical depth (AOD)}

Aerosol optical depth (AOD) is a measure of the total column extinction of transmitted radiation by atmospheric air molecules, aerosols (e.g., urban haze, smoke particles, desert dust, sea salt) and gases in the solar electromagnetic spectrum (WMO 1994).

The total optical depth $\left(\tau_{\text {tot. }}\right)$ can be obtained using the following equation according to BeerLambert law,

$$
V=\left(V_{0} / d^{2}\right) \exp \left(-\tau_{\text {tot. }}(\lambda) m\right),
$$

where $V$ is the digital voltage measured at wavelength $\lambda$, by a sun photometer and is proportional to the spectral irradiance $(I)$ reaching the instrument at the surface. $V_{0}$ is the extraterrestrial voltage. $I_{0}$ and $V_{0}$ are estimated at the top of the atmospheric irradiance and corresponding voltages, respectively. $d$ is the ratio of the average to the actual Earth-Sun distance, $\tau_{\text {tot. }}$ is the total optical depth and $m$ is the optical airmass (Holben et al. 1998). For obtaining the AOD, the measured optical thickness of atmosphere has to be corrected as:

$$
\tau_{\text {aer }}(\lambda)=\tau_{\text {tot. }}(\lambda)-\tau_{\mathrm{R}}(\lambda)-\tau_{g}(\lambda),
$$

where $\tau_{\text {tot. }}(\lambda)$ is the total atmospheric optical depth, $\tau_{\mathrm{R}}$ is the component due to Rayleigh scattering, and $\tau_{g}$, is the optical depth due to ozone, nitrogen dioxide and water vapor. The ozone contribution to optical depth only becomes significant for wavelengths $<330 \mathrm{~nm}$ while the $\mathrm{NO}_{2}$ contribution is very small over the whole wavelength range (Brogniez et al. 2008).

The amount of water vapour is estimated from the solar intensity measurements at $936 \mathrm{~nm}$ (water absorption peak) and $1020 \mathrm{~nm}$ (no absorption by water) in $\mathrm{cm}$ (integrated columnar water vapour 
thickness). Therefore, AOD can be easily obtained in wavelengths of non-absorption (Gueymard 1994).

\subsection{Angstrom turbidity formula}

Angstrom suggested an empirical formula for the attenuation of scattering and absorption by aerosols. According to his formula, the AOD, $\tau_{\text {aer }}(\lambda)$, is related to wavelength $(\lambda$ in $\mu \mathrm{m})$ through Angstrom's equation:

$$
\tau_{\text {aer }}=\beta \lambda^{-\alpha},
$$

where $\alpha$ and $\beta$ are known as Angstrom parameters. The Angstrom exponent, $\alpha$ is related to the size distribution of the aerosol particles. Large values of $\alpha$ indicate a relatively high ratio of small particles to large particles It varies in the range of $0-4$ approaching 4 , when the aerosol particles are very small (i.e., the order of air molecules) and zero for very large particles. Mid-range values of $\alpha(\alpha>2)$ are typically observed for particles in the accumulation mode (Nakajima and Higurashi 1998; Eck et al. 1999; Reid et al. 1999) and lower values (near to 0) have been observed for Saharan dust episodes and coarse mode particles (Eck et al. 1999; Smirnov et al. 2000). Generally, $\alpha$ has a value between 0.5 and 2.5 (Iqbal 1983), but based on the Angstrom suggestion the value of 1.3 is commonly employed (Angstrom 1964). A suitable average value of $\alpha$ for the most natural atmospheres is about $1.3 \pm 0.5$ (Iqbal 1983).

The Angstrom turbidity coefficient $(\beta)$ represents the amount of aerosols present in the atmosphere in the vertical direction, and generally its value varies from 0.0 to 0.5 . The value of $\beta<0.1$ indicates a clean atmosphere, while $\beta>0.1$ depicts a turbid atmosphere. In fact, according to equation (3), $\beta$ is the AOD at $\lambda=1 \mu \mathrm{m}$. Therefore AOD and $\beta$ usually have a similar variation. After converting the Angstrom equation (3) to a logarithmic format, it yields:

$$
\ln \tau_{\text {aer }}=\ln \alpha-\alpha \ln \lambda .
$$

There are many techniques to determine the values of $\beta$ and $\alpha$. The most accurate method is to measure the AOD at two wavelengths. The selected wavelengths are usually 440 and $675 \mathrm{~nm}$, so the effects of atmospheric extinction due to water vapour absorption and uniformly mixed gas scattering can be neglected.

\subsection{Instruments and database}

Two types of data for the city of Zanjan from December 2009 to October 2010 were used in this study. The 3-hourly meteorological data including temperature, surface pressure, wind speed and direction, relative humidity and visibility were taken from the synoptic station of Zanjan (see figure 1). The sun photometric data for a suburban area, $3 \mathrm{~km}$ away from the city center of Zanjan, were also collected. This data is produced by a multi-channel (with wavelength range of 440 to $1020 \mathrm{~nm}$ ) automatic optical instrument which measures the spectrum of direct solar irradiance. The instrument is made by the CIMEL Electronic Company and its technical information along with operational modes has been described in the CIMEL user manual (Rainwater and Gregory 2005). Direct measurements of the Sun and the sky can be made with several programmable sequences. The direct sun measurement is made in five spectral bands (440, 670, 870, 936, $1020 \mathrm{~nm}$ ) and requires approximately $10 \mathrm{~s}$. A sequence of three such measurements can be made $30 \mathrm{~s}$ apart creating a triplet observation per wavelength. The sampling interval is typically $15 \mathrm{~min}$. The specification of sun photometer (CE 318-1) standard model with 5 filters is FOV: solar collimator: $1.2^{\circ}$, sky collimator: $1.2^{\circ}$, bandwidth: $10 \mathrm{~nm}$ at full width at half maximum, detector: UV enhanced silicon detector for the Sun, silicon detector for the sky.

Atmospheric optical depth can be determined from direct solar radiation with an accuracy of $\pm(0.02-0.04)$ for an airmass factor of $2(\mathrm{~m}=2)$ (Rainwater and Gregory 2005). In order to eliminate the effects of cloud, a cloud-screening method is implemented according to Smirnov et al. (2000). The short-term variability is derived from so called 'triplets' of three observations $\tau_{1}, \tau_{2}$, and $\tau_{3}$ taken $30 \mathrm{~s}$ apart. Measurements are excluded if the triplet variability (difference between $\tau_{\max }$ and $\tau_{\min }$ ) exceeds an empirical threshold value of 0.03 . Since time periods coincident with rapid changes of AOD and very low values of $\alpha$ suggest the presence of cirrus clouds, measurements during such time periods were also removed. Therefore, $43 \%$ of measurements are excluded from further analysis.

\section{Results and discussion}

\subsection{Variations of atmospheric turbidity indices}

In the whole period of measurements (from December 2009 to October 2010), different turbidity indices including AOD, $\alpha$ and $\beta$ were calculated and statistical analysis was applied to characterize the atmospheric optical properties of Zanjan. We present the results in the next subsections.

\subsubsection{AOD time series}

More than 1000 measurements were taken by the CIMEL sun photometer in Zanjan during the 
period of study. As mentioned in last section $43 \%$ of measurements are excluded from further analysis.

Figure 2(a) shows the time series of AOD as a turbidity index for the wavelength $440 \mathrm{~nm}$. The plot is represented by about 1100 data, which include around four measurements each day. The minimum and maximum AOD is approximately 0.03 and 3.5, respectively. The most frequent dust events in the region occurred in winter, spring and early summer, causing peak values in the AOD time series (figure 2a). The 11-month mean and monthly mean values of AOD at four wavelengths with error bars showing the standard deviation of the monthly averaged value are illustrated in figure 2(b). The 11-month mean of AOD at the four wavelengths $1020,870,675$ and $440 \mathrm{~nm}$ is $0.17 \pm$ $0.14,0.18 \pm 0.13,0.20 \pm 0.14$ and $0.27 \pm 0.15$, respectively. Figure 2(b) also shows significant seasonal variations of AOD. The mean value of $A O D$ is high in the late spring and early summer with a peak in June.

The variations of AOD in this region may be attributed to different weather conditions. Zanjan is affected by continental airmass coming from North Africa, Saudi Arabia and Iraq. From figure 2(a), it is obvious that the median value is more representative than the mean which will be biased highly by the spikes. The mean AOD in July and August was a little lower than in June, but was also high, showing the impact of presence of dust aerosols after dust events in the late spring and regional weather conditions, such as high value of sun shine, temperature and pollutants in atmosphere.

\subsubsection{Diurnal behaviour of $A O D$}

Diurnal variability of AOD is important for various applications, including satellite aerosol data validation, radiative forcing computations, public health and studies of aerosol interaction with clouds (Kaufman et al. 2001; Smirnov et al. 2002). Values of AOD show diurnal changes throughout a year because of changes in atmospheric parameters. Figure 3 displays the diurnal mean variations of AOD in the Zanjan area for one year. The mean diurnal variation is between 0.25 and 0.29 for the wavelength of $440 \mathrm{~nm}$ which corresponds to about $15 \%$ variation Smirnov et al. (2002) based on the analysis of the diurnal cycle

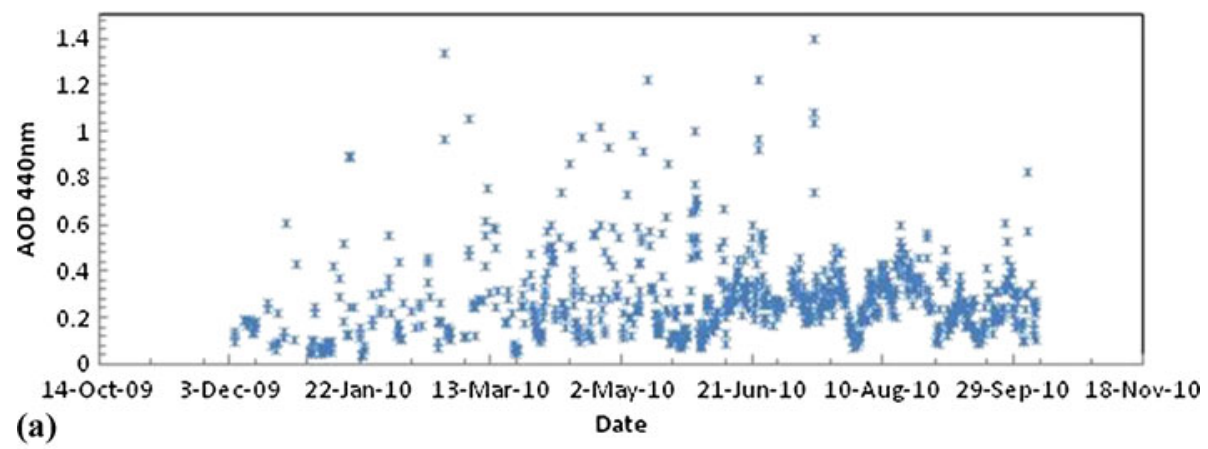

(a)

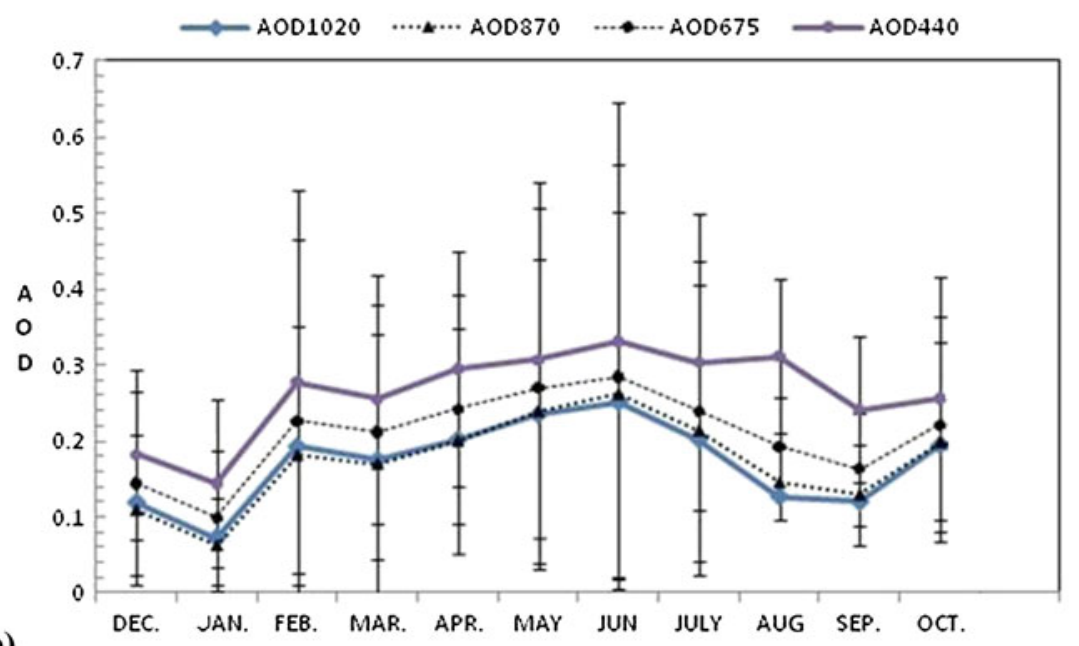

(b)

Figure 2. (a) Time series of AOD from December 2009 to October 2010: High values of AOD related to dust event in spring and summer time. (b) Monthly mean variation of AOD at four wavelengths 1020, 870, 675, $440 \mathrm{~nm}$ in Zanjan area. 
over major urban/industrial areas within the network, showed a prevailing pattern of the optical depth in which AOD increases by 10-40\% during the day at most sites. The difference is mainly due to difference in composition of aerosol (dust and industrial pollutants) and climate conditions (Liu et al. 2008). The diurnal variability of AOD in Zanjan was significant and its variety is about less than $9 \%$ in spring and winter, and more than $17 \%$ in summer and autumn (not shown).

On a diurnal scale, AOD decreases from morning to noon-time and then increases in the afternoon due to higher air temperature, lower relative humidity and higher midday wind speed. According to results of Smirnov et al. (2002) and Xia et al. (2006) the AOD increased throughout the daytime and reached a maximum in the afternoon for most urban/industrial areas. Referring to the distribution of $\alpha$ in figure 4, $\alpha$ index ranges from 0.001 to 1.67 with significant hourly and daily variations. Lower values of $\alpha$ indicate coarse mode particles (Eck et al. 1999). Dust is much coarser than industrial pollution and secondary particles on average. Higher values of $\alpha(\alpha>2)$ are typically observed for accumulation mode particles (Nakajima and
Higurashi 1998; Reid et al. 1999) and lower values (near to 0.0) have been observed for Saharan dust episodes and coarse mode particles (Eck et al. 1999). Industrial pollutants are considered to be a secondary contributor to AOD variations in the study area.

\subsubsection{Variations of atmospheric turbidity}

Atmospheric optical properties vary from day to day and month to month. Figure 5 shows the 11month mean and monthly mean variation of $\alpha, \beta$ and precipitable water vapour during the period of study. The 11-month mean and standard deviation of $\alpha$ is equal to $0.73 \pm 0.38$. Low values of $\alpha$ were recorded during June implying that coarse mode aerosols predominate during this month. The result is in agreement with heavy dust events in figure 2 (a and $\mathrm{b}$ ). The $\alpha$ index decreases from March to June, then it increases from June to August and also from December to January (figure 5). These variations depend on the frequency of precipitation since rain would clear the sky from dust.

The 11-month mean and standard deviation of $\beta$ is equal to $0.17 \pm 0.14$. Due to the influence

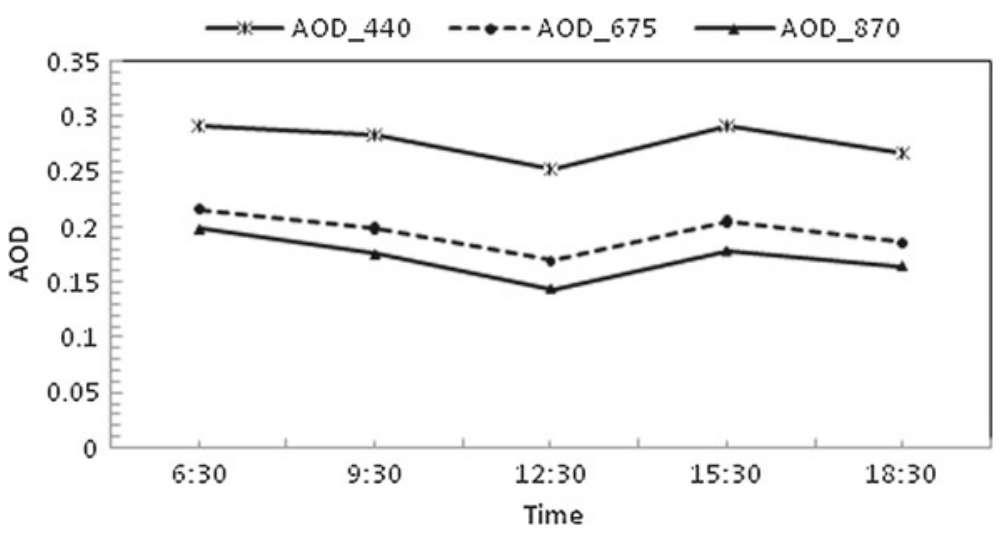

Figure 3. Diurnal variability of AOD, for the wavelength of 440, 675, $870 \mathrm{~nm}$ for years 2009-2010 in Zanjan.

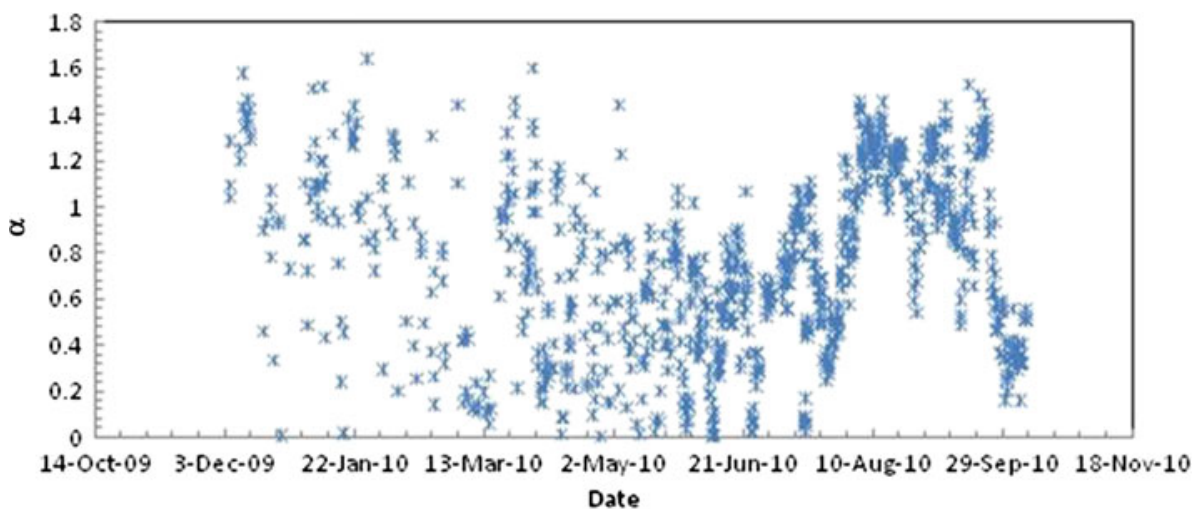

Figure 4. Temporal variation of $\alpha$ at Zanjan during December 2009 to October 2010. 


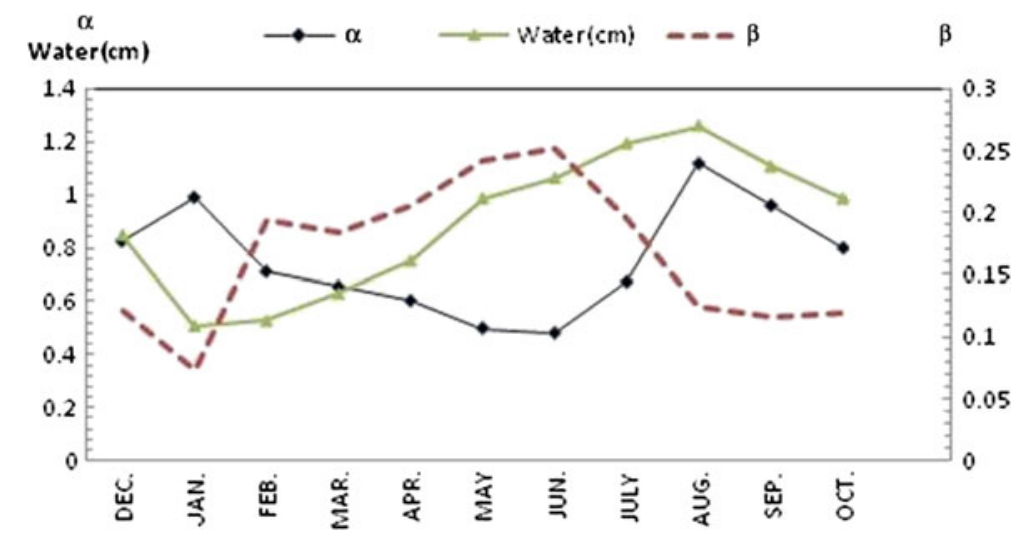

Figure 5. Monthly variation of mean values of $\beta, \alpha$ and precipitable water vapour.

of dust activities in Zanjan, the $\beta$ index increases from March to June, reaching the maximum value, followed by a decrease and approaching the minimum value in September. The lowest value of $\beta$ appears in the winter, especially in January.

The high values of $\beta$ and low values of $\alpha$ in April, May, June and July coincide with the highest frequency of dust events and consequent coarse particles. In January, low values of $\beta$ are associated with the passage of weather systems making atmospheric instability and precipitation in the Zanjan area. In figure 5 , on a monthly scale, it is seen that there is an anti-correlation between $\alpha$ and $\beta$ indicating continuous redistribution of fine and coarse particles under the influence of meteorological parameters.

It is also worth mentioning that high values of $\alpha$ (figure 5) are consistent with high AOD values (figure 2b) in July and August, which is possibly caused by the enhancement in the contribution of fine particles during high temperature period (Lyamani et al. 2006).

The maximum and minimum of precipitable water vapour in the atmosphere of Zanjan at wavelength $936 \mathrm{~nm}$ is between 0.1 and $2.2 \mathrm{~cm}$, occurring in February and August, respectively (not shown).

The existence of weak correlation between $\beta$ and precipitable water vapor in this study can be attributed to the fact that turbidity does not likely depend on precipitable water vapour in the atmosphere of Zanjan.

The Angstrom exponent dependence on AOD was used to achieve the aerosol size distribution (e.g. D'almeida 1987; Fouquart et al. 1987; Cheng et al. 2006). Figure 6 shows the relationship between AOD and $\alpha$ that determines the dependence of aerosol loading on particle size, for winter, spring, summer and autumn in Zanjan. An exponential dependence of alpha on AOD in spring and winter indicate that dust aerosols are major contributor to the atmospheric turbidity in Zanjan. There is no obvious relationship between $\alpha$ and AOD for the two other seasons. It means that a mixture of different aerosol types including fine mode (urban pollution) and coarse mode (dust) aerosols can be found in Zanjan atmosphere in these seasons. This relationship is seen on both the seasonal and diurnal timescale showing the importance of meteorological parameters on the aerosol amounts and properties. According to Cheng et al. (2006) findings, this may show that the sources of aerosols in Zanjan vary with seasons.

In the Zanjan area, there is a background level of aerosols which is dominated by accumulation mode aerosols, associated with relatively high $\alpha$ and low $\beta$. This is regularly augmented by dust episodes bringing large particles and thereby reduction of $\alpha$; so $\alpha$ and $\beta$ show an anti-correlation in dataset (figure 5). The higher value of $\beta$ (and smaller value of $\alpha$ ) during winter and spring signifies higher relative abundance of coarse (super micron) aerosols in the atmosphere. More than 30 cases of clean and high turbid atmosphere were considered in this study.

The variation of measured AOD and $\alpha$ during turbid days (15 July, 23 February, 24 June, 15 March 2010) and clean days without dust (10 December 2009; 22 March, 11 June, 30 July, 2, 18 August 2010) are shown in figure 7. This figure show that on July 15, April 6, February 23, June 24 and March 15 2010, AOD was wavelength independent during various times of turbid days (wavelength independent of AOD is a characteristic of large particles, figure 5a). However, there is also large population of points corresponding to low $\alpha$ and high AOD indicating presence of dust aerosols especially despite large AOD, $\alpha$ values decrease with increasing AOD.

This further indicates that coarse aerosols dominate and also that the ratio of coarse/fine aerosols increases, under conditions of high turbidity. The generalized trend noted in this region is in good agreement with the observed pattern at several other locations for different aerosol types 

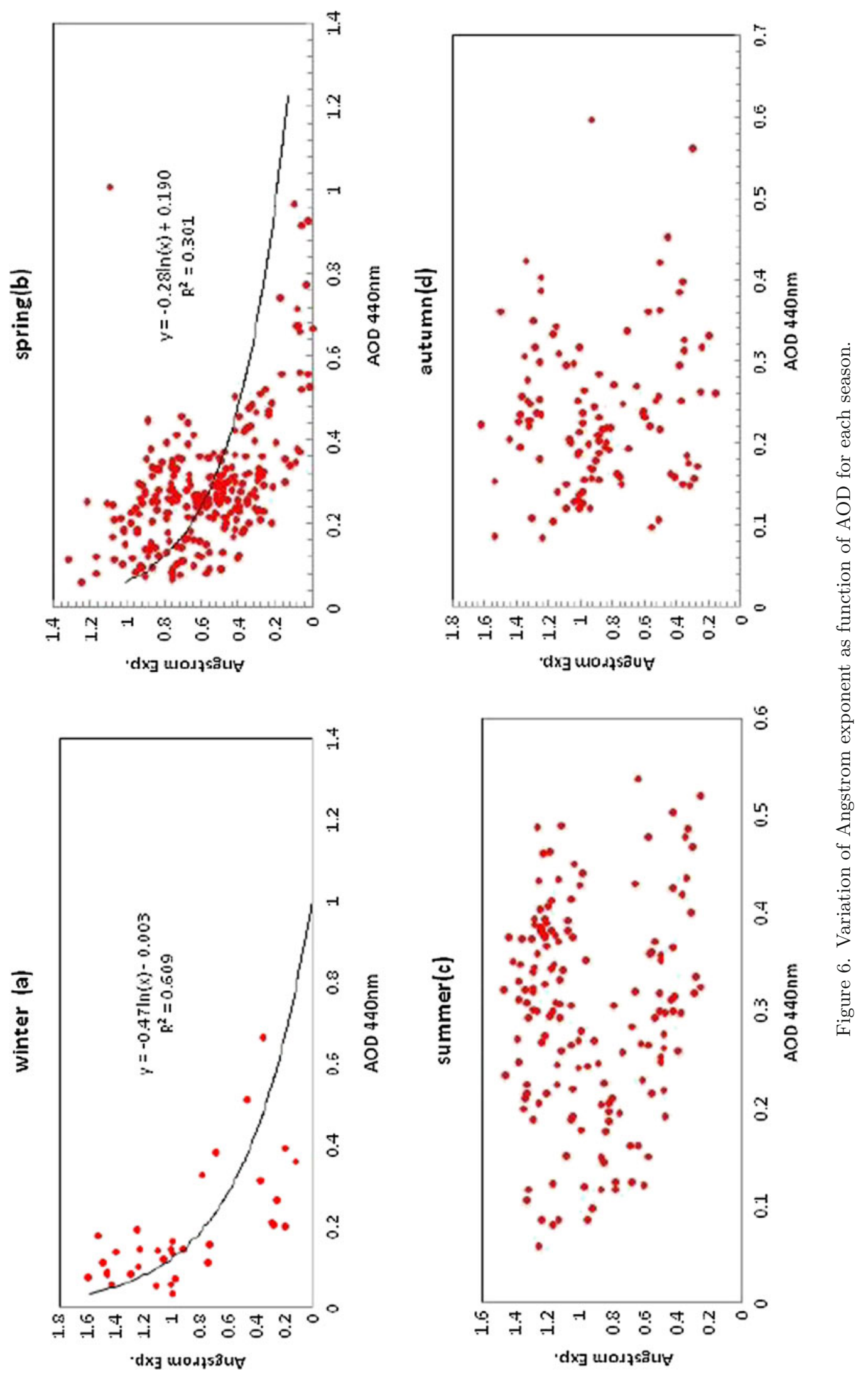

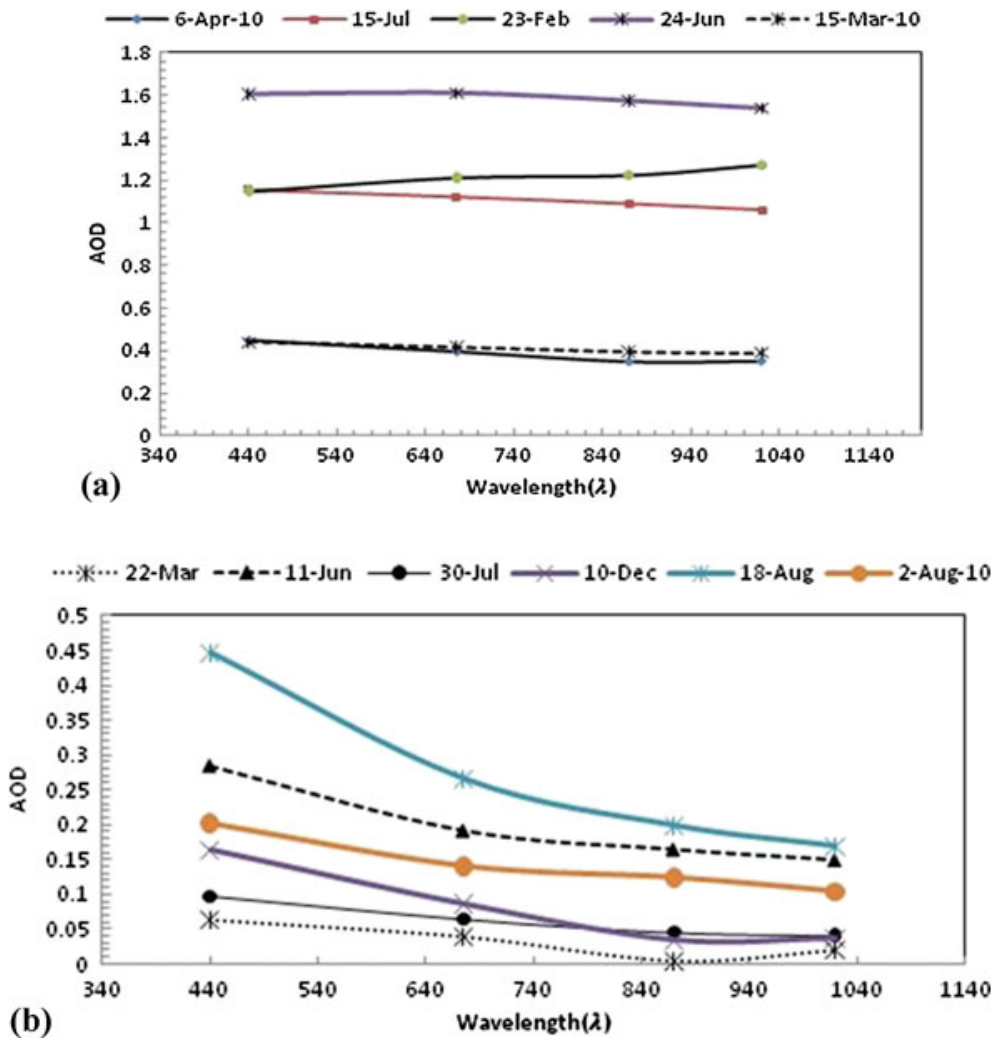

Figure 7. Variation of AOD with wavelength associated with (a) turbid and (b) clean days.

(e.g., Moorthy and Satheesh 2000; Cheng et al. 2006; Kaskaoutis et al. 2007). On these days, $\beta$ exceeds 0.4 and even reaches 1.6; the particles size increased, as the Angstrom exponent varied from 0.2 to near zero.

According to the Zanjan synoptic station data, on these days, weather conditions included visibility of $3-6 \mathrm{~km}$, with westerly-southwesterly winds bringing dust from Iraq deserts (figure 8a).

In the absence of large concentrations of airborne dust and sea salt particles, AOD at visible wavelengths are strongly influenced by fine mode aerosols. In contrast the turbid days are characterized by rather flat AOD spectra that can be attributed to a significant impact of coarse aerosols (Satheesh et al. 2006).

On 18th August, an increase in the values of $\alpha$ with corresponding increase in AOD indicated the contribution of small particles in the atmosphere during or mixture of other aerosols (in fine mode) as a mixture of desert dust and urban pollution. $\alpha$ and $\beta$ are about 1.21 and 0.16 , respectively (reflecting the existence of accumulation mode and mixed type aerosols).

On December 10, 2009; March 22, June 11, July 30 and August 2, 2010, the AOD is dependent on wavelength, a characteristic of small particles. On these days Angstrom exponent was about, 1 to 1.5 which corresponds to dominations of particles in accumulation mode, and $\beta$ varying between about 0.04 to 0.1 , which is not a characteristic for dusty days.

For comparison between turbid and clean days, airmass backward trajectories were calculated for 15 and 30 July and are given in figure 8. Airmass backward trajectories were calculated with the HYbrid Single-Particle Lagrangian Integrated Trajectory (HYSPLIT4) model (http://www.arl.noaa, NOAA Air Resources Laboratory, Silver Spring, MD). The analysis was carried out at the level of $500 \mathrm{~m}$ (well within the Atmospheric Boundary Layer, ABL, Moorthy et al. 2005). Results show that the transports of aerosols are from the west of the Middle East and particularly from deserts of Iraq, which contributed significantly to the increase of AOD and atmospheric turbidity. As this airmass traverses the vast desert and arid regions, it is rich in coarse dust aerosols, which contribute to the observed features; such as the increase in AOD and $\beta$ and decrease in $\alpha$ (figure 8a). Figure 8(b) shows that the atmospheric flow was bringing clear airmass from the Caspian Sea towards the region of study.

\subsection{Turbidity analysis}

The frequency distribution of $\beta$ is shown in figure 9 . This figure indicates that more than $27 \%$ 


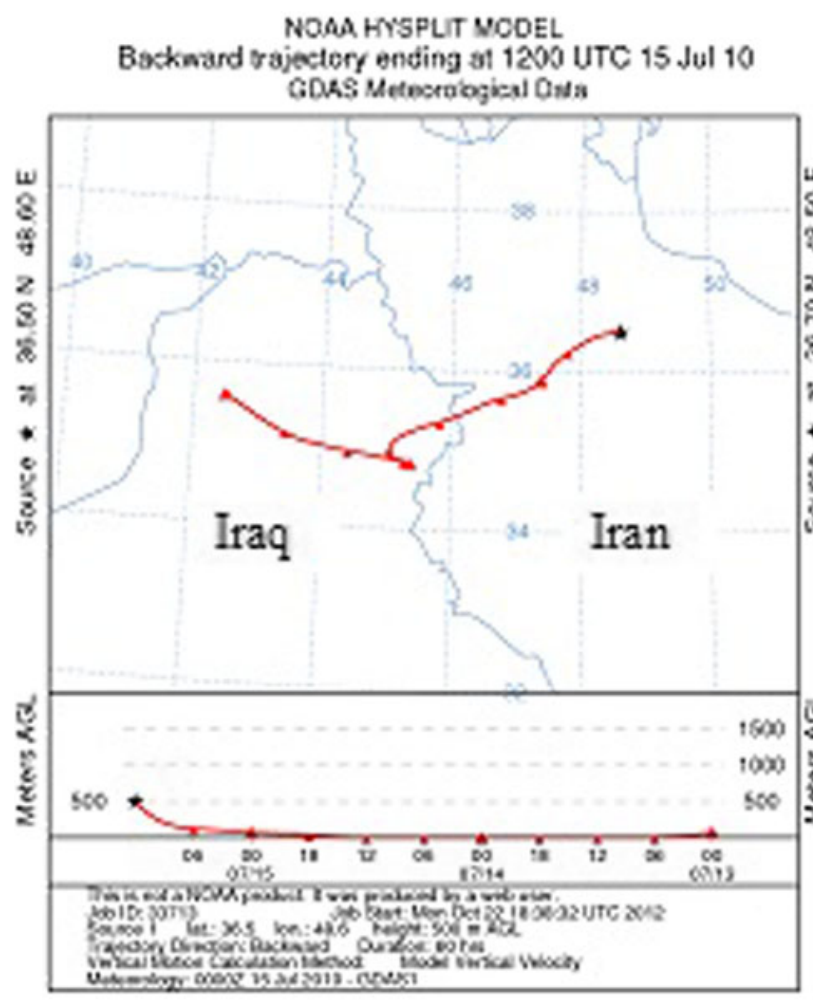

(a)

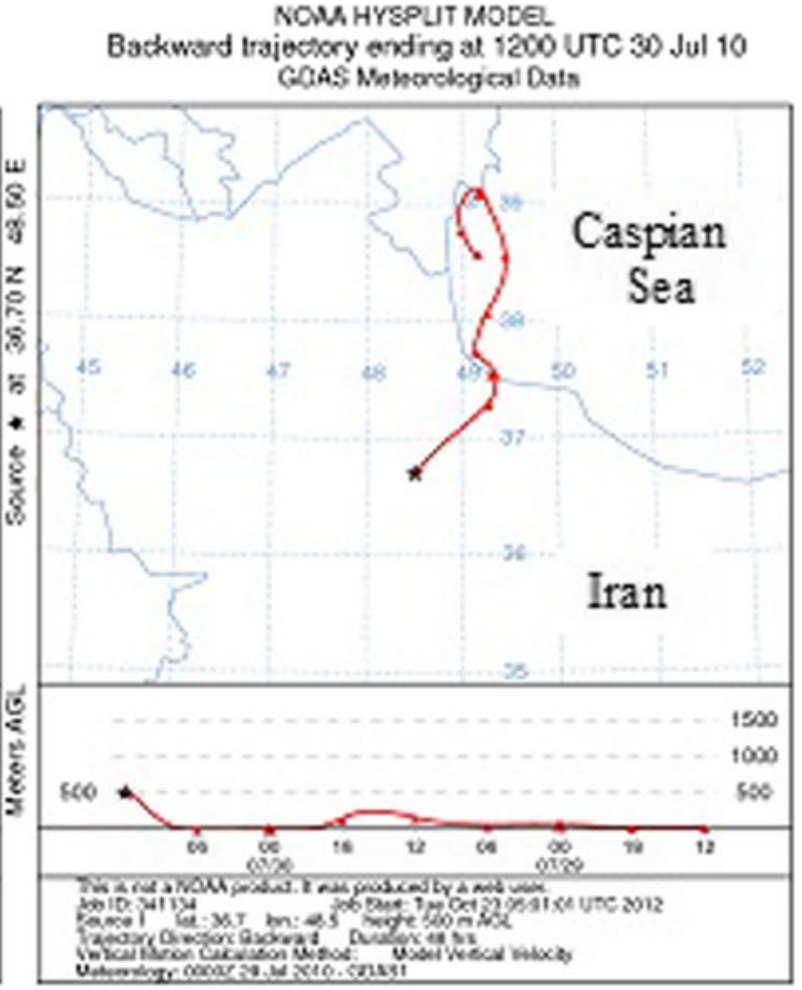

(b)

Figure 8. Back trajectory of the air parcel for 48 hours ending at 12 UTC 15th (a) and 30th (b) July 2010 using NOAA HYSPLIT model.

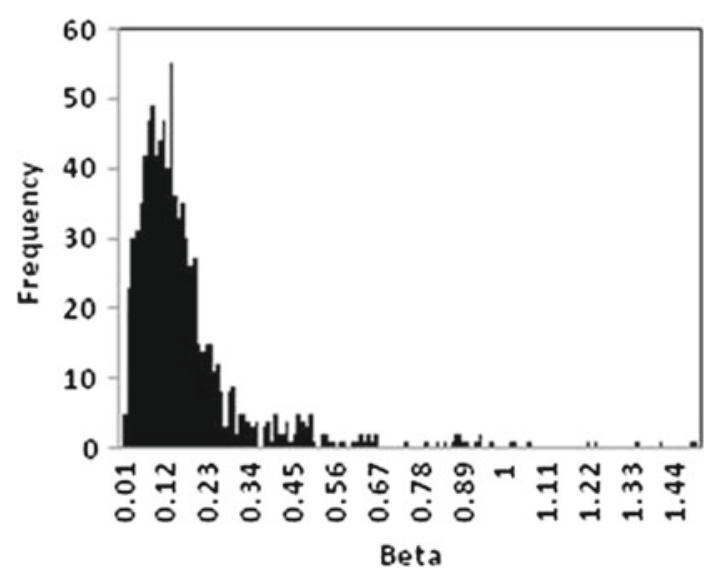

Figure 9. Frequency distribution of $\beta$ during December 2009 to September 2010 in Zanjan.

of $\beta$ values exceed 0.2 , corresponding to a very turbid condition; about $42 \%$ of $\beta$ values lie between $0.1-0.2$ (moderate turbidity) and nearly $30 \%$ of $\beta$ are below 0.1 (low turbidity). The most frequent value of $\beta$ occurs in the range $0.07-0.19$. About $30 \%$ of $\alpha$ values are in the fine mode of atmospheric aerosols $(\alpha=1.3 \pm 0.5)$ and about $70 \%$ of aerosols are in the coarse mode, consistent with the prevalence of dust events.

To show the effect of wind direction on atmospheric turbidity, values of Angstrom indices asso- ciated with categories of wind direction along with event frequency and wind speed are illustrated in table 1. It is seen that the predominant winds in the Zanjan area during the period of this study were the northeasterly (NE) and southwesterly (SW) winds. According to this table, the WSW-SWSSW winds could be the main reason of the highest $\beta$ around 0.28 . These winds transport the coarse mode particles toward the city of Zanjan. It is worth mentioning that most of the dust events happened when the dominant wind direction was WSW.

Based on the results of Chang (1999) and Tsai and Cheng (1999), high wind speeds cause particles accumulation and advection which in turn affects air quality. Here the effect of wind speed on atmospheric turbidity in Zanjan is presented in table 1. From this table it is obvious that wind speeds above $4 \mathrm{~m} / \mathrm{s}$ cause atmospheric turbidity, $\beta$ around 0.2 , because of an increase in the number of suspended particles, as found by Katz et al. (1989).

For the southerly and westerly wind directions, the mean wind speeds are generally above $4 \mathrm{~m} / \mathrm{s}$ and most of the turbidity coefficients are above 0.2 , while for the easterly and northerly wind directions with mean wind speeds of about $5 \mathrm{~ms}^{-1}$ the turbidity values are less than 0.15 . The strongest wind speeds in these directions are likely coming from 
Table 1. Wind speed, direction and event frequency with $\alpha$ and $\beta$ values.

\begin{tabular}{lcccc}
\hline $\begin{array}{l}\text { Wind speed } \\
(\mathrm{m} / \mathrm{s})\end{array}$ & $\alpha$ & $\beta$ & $\begin{array}{c}\text { Frequency } \\
(\%)\end{array}$ & $\begin{array}{c}\text { Wind } \\
\text { direction }\end{array}$ \\
\hline $0-1$ & 0.57 & 0.18 & 28 & $\mathrm{~N}$ \\
4.8 & 0.85 & 0.11 & 3 & $\mathrm{NNE}$ \\
5.5 & 1.1 & 0.12 & 5 & $\mathrm{NE}$ \\
4 & 0.78 & 0.15 & 16 & $\mathrm{ENE}$ \\
3.6 & 0.74 & 0.16 & 11 & $\mathrm{E}$ \\
4 & 0.82 & 0.16 & 6 & $\mathrm{ESS}$ \\
3.3 & 0.61 & 0.14 & 1 & $\mathrm{SE}$ \\
3.5 & 0.61 & 0.14 & 1 & $\mathrm{SSE}$ \\
3.6 & 0.64 & 0.22 & 3 & $\mathrm{~S}$ \\
4 & 0.46 & 0.2 & 2 & SSW \\
4.6 & 0.49 & 0.23 & 1 & SW \\
4.3 & 0.48 & 0.28 & 9 & WSW \\
3.7 & 0.71 & 0.16 & 9 & W \\
3.6 & 0.69 & 0.18 & 4 & WNW \\
2.8 & 0.59 & 0.2 & 1 & NW \\
3 & 0.63 & 0.2 & 1 & NNW \\
\hline
\end{tabular}

the Manjil Valley and the Caspian Sea, which are not sources of dust.

\section{Conclusions}

Aerosol optical properties in the city of Zanjan $\left(36^{\circ} \mathrm{N}, 43^{\circ} \mathrm{E}\right)$, located around $1700 \mathrm{~m}$ above sea level, including Aerosol Optical Depth (AOD), Angstrom exponent $(\alpha)$, and Angstrom turbidity coefficient $(\beta)$ were studied from December 2009 to October 2010 using the sun photometric and meteorological data. It was found that the turbidity varies on all time scales, from hourly to seasonal.

The diurnal variation of AOD is between 0.25 and 0.29 for wavelength $440 \mathrm{~nm}$ which corresponds to about $15 \%$ of variations. The 11 -month mean averages and standard deviations of AOD at four wavelengths of $1020,870,675$ and $440 \mathrm{~nm}$ are about $0.17 \pm 0.14,0.18 \pm 0.13,0.20 \pm 0.14$ and $0.27 \pm$ 0.15 , respectively. Also, the 11-month averages and standard deviations of $\alpha$ and $\beta$ are $0.73 \pm 0.38$ and $0.17 \pm 0.14$, respectively. The minimum monthly mean of $\mathrm{AOD}_{440}$ appears in January with value of about 0.14 , while the maximum value exists in June with amount of 0.33 .

The value of $\beta$ is low and constant during January, but it increases in spring and summer months. In fact, an increasing trend of $\beta$ value is observed from April to June, followed by a decrease until September. The lowest value of $\beta$ occurs in winter, especially in January, and the highest value of turbidity is in late spring and early summer when there are frequent dust events. Low values of $\alpha$ take place from March to June, indicating that large aerosol particles are prominent in this period. In monthly time scale, it is seen that there is an anti-correlation between $\alpha$ and $\beta$ indicating continuous redistribution of fine and coarse particles under the influence of meteorological conditions.

An exponential dependence of $\alpha$ on AOD in spring and winter indicates that the dust aerosols are major contributors of atmospheric turbidity in Zanjan. There is no obvious relationship between $\alpha$ and AOD for summer and autumn.

The seasonally changing wind pattern transports aerosols of different characteristics to the Zanjan area. During February, spring and early summer winds transport continental aerosols mostly from Iraq (dust events) and in other times of the year it is dominated by aerosols in accumulation mode in summer, especially in August.

The other noticeable point is that precipitable water vapor has no significant impact on the atmospheric turbidity in the study region as the air in this region is often dry.

Based on the results, the predominant wind directions are $\mathrm{N}-\mathrm{NE}$ and $\mathrm{S}-\mathrm{SW}$ in this region. The highest $\beta$ with value of about 0.28 was found for SW winds. In addition, most dust events happened when the wind direction was W-SW. It was also shown that AOD is strongly affected by the airmass sources. Airmass backward trajectories show that the transport of aerosols, particularly from the west of the Middle East and deserts of Iraq, contributed significantly to the increase of $\beta$ and atmospheric turbidity.

\section{Acknowledgements}

The authors would like to greatly thank Professor G Vaughan from the School of Earth, Atmospheric and Environmental Sciences of the University of Manchester for his technical support and revision of this paper. We also acknowledge the support of Iranian Meteorological Organization and Institute for Advanced Studies in Basic Sciences (IASBS) of Zanjan for data acquisition for this work.

\section{References}

Andreae M O 1995 Climatic effects of changing atmospheric aerosol levels in World Survey of Climatology 16; In: Future climates of the world (ed.) Henderson-Sellers A (New York: Elsevier), 341p.

Angstrom A 1964 The parameters of atmospheric turbidity; Tellus. 16 64-75.

Braslau N and Dave J 1973 Effect of aerosols on the transfer of solar energy through realistic model atmospheres. Part 2: Partly absorbing aerosols; J. Appl. Meteorol. 12 616-619. 
Brogniez C, Buchard B and Auriol F 2008 Validation of UVvisible aerosol optical thickness retrieved from spectroradiometer measurements; Atmos. Chem. Phys. Discuss 8 3895-3919.

Cachorro V E, Vergaz R and de Frutos A M 2001 A quantitative comparison of Angstrom turbidity parameter retrieved in different spectral ranges based on spectroradiometer solar radiation measurements; Atmos. Environ. 35 5117-5124.

Canada J, Pinazo J M and Bosca J V 1993 Determination of Angstrom turbidity coefficient at Valencia; Renew. Energy 3 621-626.

Chang J 1999 The relationship of visibility with physical and chemical characteristics of suspended particles in Kaohsiung City; Master Thesis, National Sun Yat-Sen University, Kaohsiung, Taiwan.

Cheng T, Wang H, Xu Y, Li H and Tian L 2006 Climatology of aerosol optical properties in Northern China; Atmos. Environ. 40 1495-1509.

Chih-Chung Wen and Hui-HsuanYeh 2010 Comparative influences of airborne pollutants and meteorological parameters on atmospheric visibility and turbidity; Atmos. Res. 96 496-509.

Coakley J A, Cess R D and Yurevich F B 1983 The effect of tropospheric aerosols on the Earth's radiation budget; A parameterization for climate models; J. Atmos. Sci. $\mathbf{4 0}$ $116-138$.

Coakley J A and Cess R D 1985 Response of the NCAR Community Climate Model to the radiative forcing by the naturally-occurring tropospheric aerosol; J. Atmos. Sci. 42 1677-1692.

Cucumo M, Marinelli V and Oliveti G 1999 Experimental data of the Linke turbidity factor and estimates of the Angstrom turbidity coefficient for Tow Italian localities; Renew. Energy 17 390-410.

Cucumo M, Kaliakatsos D and Marinelli V 2000 A calculation method for the estimation of the Linke turbidity factor; Renew. Energy 19 249-258.

D'almeida G A 1987 On the variability of desert aerosol radiative characteristics; J. Geophys. Res. 92 3017-3026.

Eck T F, Holben B N, Reid J S, Dubovik O, Smirnov A, O'Neill N T, Slutsker I and Kinne S 1999 Wavelength dependence of the optical depth of biomass burning, urban, and desert dust aerosol; J. Geophys. Res. 104 $31,333-31,349$.

Fouquart Y B, Bonnel M C, Roquai R and Santer A Cerf 1987 Observations of Saharan aerosols: Results of ECLATS field experiment. Part I: Optical thickness and aerosol size distributions; J. Appl. Meteorol. 26(1) 28-37.

Gueymard C A 1994 Analysis of monthly average atmospheric precipitable water and turbidity in Canada and Northern United States; Sol. Energy 53 57-71.

Gueymard C A and Garrison J D 1998 Critical evaluation of precipitable water and atmospheric turbidity in Canada using measured hourly solar irradiance; Sol. Energy 62 291-307.

Gueymard C A and Vignola F 1998 Determination of atmospheric turbidity from the diffuse-beam broadband irradiance ratio; Sol. Energy 63 135-146.

Hainel G, Weidert D and Busen R 1990 Absorption of solar radiation in an urban atmosphere; Atmos. Environ. 24 283-292.

Hand J L, Kreidenweis S M, Slusser J and Scott G 2004 Comparison of aerosol optical properties derived from sun photometry to estimates inferred from surface measurements in Big Bend National Park Texas; Atmos. Environ. 38 6813-6821.

Holben B N, Eck T F, Slutsker I, Tanre D, Buis J P, Setzer A, Vermote E, Reagan J A, Kaufman Y, Nakajima T,
Lavenu F, Jankowiak I and Smirnov A 1998 AERONET A federated instrument network and data archive for aerosol characterization; Rem. Sens. Environ. 66 1-16.

Hussain M, Khatun S and Rasul N G 2000 Determination of atmospheric turbidity in Bangladesh; Renew. Energy 20 325-332.

Iqbal M 1983 An introduction to solar radiation (New York: Academic Press), 256p.

Jacovides C, Varotsos C and Kaltsounides N 1994 Atmospheric turbidity parameters in the highly polluted site of Athens basin; Renew. Energy 4 465-470.

Kaskaoutis D G, Kambezidis H D, Hatzianastassiou N, Kosmopoulos P G and Badarinath K V S 2007 Aerosol climatology: On the discrimination of aerosol types over four AERONET sites; Atmos. Chem. Phys. Discuss 7 6357-6411.

Katz M, Bailie A and Mermier M 1989 Atmospheric turbidity in a semi-rural site. I: Influence of climatic parameters; Sol. Energy 4 323-328.

Kaufman Y J and Fraser R S 1983 Light extinction by aerosols during summer air pollution; J. Clim. Appl. Meteorol. 22 1694-1725.

Kaufman Y J, Didier Tam, Dubovik A and Karnieli L A 2001 Remer absorption of sunlight by dust as inferred from satellite and ground-based remote sensing; Geophys. Res. Lett. 28 1479-1482.

Kiehl J T and Breigleb B P 1993 The radiative roles of sulfate aerosols and green house gases in climate forcing; Science 260 311-314.

Kokhanovsky A A 2008 Aerosol optics, light absorption and scattering by particles in the atmosphere (Springer, Berlin: Praxis Publication Ltd.), 149p.

Lelieveld J 2001 The Indian Ocean experiment: Widespread air pollution from south and southeast Asia; Science 291 1031-1036.

Liu J, Zheng Y, Zh Li and Wu R 2008 Ground based remote sensing of optical properties in one city north west China; Atmos. Res. 89 194-205.

Lodhi N K, Beegum S N, Singh S and Kumar K 2013 Aerosol climatology at Delhi in the western Indo-Gangetic Plain: Microphysics, long-term trends, and source strengths; J. Geophys. Res. 118 1361-1375, doi:10.1002/jgrd.50165.

Lyamani H, Olmo F J, Alcantara A and Alados-Arboledas L 2006 Atmospheric aerosols during the 2003 heat wave in southeastern spain. I: Spectral optical depth; Atmos. Environ. 40 6453-6464.

Moorthy K K and Satheesh S K 2000 Characteristics of aerosols over a remote island, Minicoy in the Arabian Sea: Optical properties and retrieved size characteristics; Quart. J. Roy. Meteorol. Soc. 126 81-109.

Moorthy K K, Babu S S and Satheesh S K 2003 Aerosol spectral optical depths over the Bay of Bengal: Role of transport; Geophys. Res. Lett. 305 1249, doi:10.1029/ 2002GL016520.

Moorthy K, Babu S and Satheesh S 2005 Aerosol characteristics and radiative impacts over the Arabian Sea during the inter monsoon season: Results from ARMEX field campaign; J. Atmos. Sci. 62 192-206.

Nakajima T and Higurashi A 1998 A use of two-channel radiances for an aerosol characterization from space; Geophys. Res. Lett. 25 3815-3818.

Ogunjobi K O, He Z and Simmer C 2008 Spectral aerosol optical properties from AERONET Sun-photometric measurements over west Africa; Atmos. Res. 88 89-107.

Ping Guo J, Xiao-Ye Zhang, Hui-Zheng Che, Sun-Ling Gong, Xingqin An, Chun-Xiang Cao, JieGuang, Hao Zhang, Ya-Qiang Wang, Xiao-Chun Zhang, Min Xue and XiaoWen Li 2009 Correlation between PM concentrations and 
aerosol optical depth in eastern China; Atmos. Environ. 43 37-51.

Polavarapu R J 1978 Atmospheric turbidity over Canada; J. Appl. Meteorol. 17 1368-1374.

Rainwater M and Gregory L 2005 www.arm.gov, publications, technical reports, instruments handbook, CIMEL Sun photometer, DOE/SC-ARM/TR-056.

Ramanathan V, Crutzen P J and Lelieveld J 2001 Indian Ocean experiment: An integrated analysis of the climate forcing and effects of the great Indo-Asian haze; J. Geophys. Res. Atmos. 106 28,371-28,398.

Rapti A S 2000 Atmospheric transparency, atmospheric turbidity and climatic parameters; Sol. Energy $\mathbf{6 9}$ 99-111.

Reid J S, Eck T F, Christopher S A, Hobbs P V and Holben B 1999 Use of the Angstrom exponent to estimate the variability of optical and physical properties of aging smoke particles in Brazil; J. Geophys. Res. 104 $27,473-27,489$.

Satheesh S K and Ramanathan V 2000 Large differences in the tropical aerosol forcing at the top of the atmosphere and Earth's surface; Nature 405 60-63.

Satheesh S K and Moorthy K 2005 Radiative effects of natural aerosols: A review; Atmos. Environ. 392089 2110.

Satheesh S K, Krishna Moorthy K, Kaufman Y J and Takemura T 2006 Aerosol optical depth physical properties and radiative forcing over the Arabian Sea; Meteorol. Atmos. Phys. 91 45-62, doi:10.1007/s00703-004-0097-4.

Seinfeld H and Pandis N 1998 Atmospheric chemistry and physics, from air pollution to climate change (New York: John Wiley and Sons), 1191p.

Smirnov A, Holben B N, Eck T F, Slutsker I, Chatenet B and Pinker R T 2002 Diurnal variability of aerosol optical depth observed at AERONET (Aerosol Robotic Network) sites; Geophys. Res. Lett. 29 15-21.

Smirnov A, Holben B N, Eck T F, Dubovik O and Slutsker I 2000 Cloud screening and quality control algorithms for the AERONET database; Remote Sens. Environ. $\mathbf{7 3}$ 337-349.

Tsai Y I and Cheng M T 1999 Visibility and aerosol chemical compositions near the coastal area in central Taiwan; Sci. Total Environ. 231 37-51.

WMO 1994 Report of the WMO workshop on the measurements of atmospheric optical depth and turbidity. World Meteorological Organization Report GAW-101, 13p.

Xia X A, Chen H B, Wang P C, Zhang W X, Goloub P, Chatenet B, Eck T and Holben B 2006 Variation of column-integrated aerosol properties in a Chinese urban region; J. Geophys. Res. 111 D05204, doi: 10.1029/ 2005JD006203.

Zakey A S, Abdelwahab M M and Makar P A 2004 Atmospheric turbidity over Egypt; Atmos. Environ. 38 1579-1591. 